\title{
Eubacterium plexicaudatum sp. nov., an Anaerobic Bacterium with a Subpolar Tuft of Flagella, Isolated from a Mouse Cecum
}

\author{
TRACY D. WILKINS, R. S. FULGHUM, and J. H. WILKINS \\ Anaerobe Laboratory, College of Agriculture, Virginia Polytechnic Institute and State University, \\ Blacksburg, Virginia 24061, and Department of Microbiology, School of Medicine, \\ East Carolina University, Greenville, North Carolina 27834
}

\begin{abstract}
Fifteen strains of an anaerobic bacterium having a subpolar tuft of flagella twisted together to function as one large structure were isolated from cecal contents of ten laboratory mice, three wild mice, and a wild rat. The strains were weakly gram positive and saccharolytic, and produced butyric acid from fermented carbohydrates. Spores could not be demonstrated in any strain. The isolates formed a group that did not fit any described species of anaerobic bacterium. The name Eubacterium plexicaudatum is proposed for this organism. The type strain VPI 7582 (=ATCC 27514) was obtained from a laboratory mouse.
\end{abstract}

During studies on the flora of normal mouse ceca, we noticed large numbers of cells, each with what appeared to be a very large, subpolar flagellum which was clearly visible in wetmount preparations observed by either darkfield or phase-contrast microscopy. This unusual characteristic prompted us to attempt to isolate and identify the organism. Organisms with this distinctive morphology were isolated by use of the Hungate roll-tube procedure. The 15 isolates appeared to be unlike any described species of anaerobic bacteria and were studied in greater detail.

\section{MATERIALS AND METHODS}

Media. All media used were prepared by methods described previously (2). The organism did not grow well under $\mathrm{CO}_{2}$ due to the lowering of the initial $\mathrm{pH}$ of the culture media to approximately 6.2 ; therefore, all cultures were inoculated under oxygen-free nitrogen.

Animals. Adult, female, strain CD-1 mice were obtained from Charles River Mouse Farms, Wilmington, Mass., and were fed Purina mouse diet 5010-C. Adult, male mice were obtained from Flow Laboratories, Dublin, Va., and were fed Purina Rat Chow. Wild mice and rats were trapped alive in local farm buildings and were killed upon arrival at the laboratory.

Isolation techniques. The mice or rats were killed, and the entire cecum of each was quickly removed and placed in a tube containing $9 \mathrm{ml}$ of prereduced dilution fluid (2) with glass beads. The tube was continuously purged with oxygen-free nitrogen. The ceca in the tubes were cut into small sections with sterile forceps and scissors. The tubes were then closed anaerobically with rubber stoppers and shaken vigorously until the contents of the ceca were homogeneous and the cecal walls appeared to be free of lumen material. Serial dilutions of these suspensions were then made anaerobically in dilution fluid. Tubes containing melted and cooled $(50 \mathrm{C})$ rumen fluidglucose-cellobiose agar (2) medium were inoculated with $1 \mathrm{ml}$ of $10^{-9}$ or $10^{-10}$ dilution and spun to produce roll-tubes. After incubation for 4 to 5 days, colonies were picked at random into tubes containing $3 \mathrm{ml}$ of Sweet E (2) broth.

Culture reactions. All cultural reactions were determined with prereduced media in tubes flushed with oxygen-free nitrogen. Biochemical reactions and metabolic products of the strains were determined by methods described previously (2). The cultures were incubated at $37 \mathrm{C}$ for 3 to 6 days.

Detection of $\mathrm{H}_{2}$ gas. Analysis of the gaseous fermentation products of these strains was done by gas chromatography. The conditions of analysis were: thermal conductivity detector, $45 \mathrm{C}$; oven temperature, $45 \mathrm{C}$; copper column, 6 feet by $3 / 8$ inch (ca. 1.8 $\mathrm{m}$ by $0.95 \mathrm{~cm}$ ), packed with 100 - to 200 -mesh silica gel; and helium flow rate, $15 \mathrm{~cm}^{3} / \mathrm{min}$. Head space gas (1 $\mathrm{cm}^{3}$ ) from cultures grown in peptone-yeast extract-glucose medium (2) was injected directly into the column.

Flagella stain. King's modification of the Leifson flagella stain was used (2).

Polyhydroxybutyrate assay. The method of Law and Slepecky (3) was used for the polyhydroxybutyrate assay.

Determination of the mole percent guanine plus cytosine. The mole percent guanine plus cytosine of the type strain was determined by the thermal melting point (5) of the deoxyribonucleic acid using an automatic recording spectrophotometer and Escherichia coli $\mathrm{B}$ deoxyribonucleic acid as a standard. 


\section{RESULTS}

Isolation. Anaerobic bacteria with a coiled tuft of subpolar flagella visible to dark-field microscopy (Fig. 1) were not difficult to isolate from the ceca of either laboratory or wild mice. Total cultural counts of these organisms ranged from $10^{9}$ to $2 \times 10^{10} / \mathrm{g}$ (wet weight). Approximately $10 \%$ of the colonies were formed by organisms with this distinctive morphology. We were unable to determine the efficiency of the culture procedures due to difficulties in counting these very motile organisms in wet-mount preparations.

The organism was isolated from each of ten laboratory mice, three of four wild mice, and one of two wild rats examined. Organisms with this distinctive morphology could be seen by dark-field microscopy of the cecal contents of all animals from which the organisms were isolated; cells of this type, however, could not be seen microscopically in the ceca of those animals from which the cells were not isolated.

Morphology. All 15 isolates with microscopically visible flagella had similar cellular morphology. Upon initial isolation, the cells were slightly curved and sometimes exhibited a double curvature. The cells were approximately 1.5 to $2 \mu \mathrm{m}$ wide and 4 to $10 \mu \mathrm{m}$ long. After several transfers in culture media, the cells were thinner and usually straight. Flagella of ten could be seen at both ends of the cells with no visible indication that the cell was in the process of dividing. Flagella stains showed that the large flagellum seen in the dark-field observations was actually a tuft composed of many flagella with a subpolar origin (Fig. 2). In living cells, this tuft of flagella twisted together to form the larger structure, but the procedure used for the flagella stain caused the flagella to uncoil. After continued subculturing of certain strains, the flagella could no longer be seen by dark-field microscopy, but the tuft of flagella could always be demonstrated with a flagella stain.

The cells were originally considered to be gram negative but, when cultures less than $24 \mathrm{~h}$ old were stained, the cells stained gram positive. Some cells contained unstained areas that were slightly refractive when examined with a phasecontrast microscope. These refractile bodies were originally considered to be spores, and the organism was thought to be a clostridium. Cells showing spore-like bodies were heated at $80 \mathrm{C}$ for $10 \mathrm{~min}$ or at $70 \mathrm{C}$ for $10 \mathrm{~min}$ in starch-containing medium (2) and $\mathrm{E}$ medium (2), but in over 20 experiments the cells never survived these treatments. Cultures also were mixed with an equal volume of $95 \%$ ethanol, and after $10 \mathrm{~min}$ the cells were removed by centrifugation and suspended in fresh media. No cells survived this treatment. This evidence, combined with the observation that as many as five refractile bodies could be seen in some cells, indicated that the refractile areas were not spores. These bodies also were not polyhydroxybutyrate granules, since tests for the presence of this substance in the type strain were negative. In the absence of definitive evidence for the occurrence of spores in these organisms and because it is an anaerobic, gram-positive rod that produces butyric acid, we have placed the strains in the genus Eubacterium.

Cultural characteristics. The strains were all fastidious anaerobes which could not grow on agar plates in anaerobic jars. Colonies could be isolated by streaking the surface of roll-tubes of rumen fluid-glucose-cellobiose agar (2) or brain-heart infusion agar (2) medium. After 5 days of incubation, the colonies were $0.5 \mathrm{~mm}$ in diameter, convex, translucent, and shiny with an irregular edge. In the lower portions of the roll-tubes, the organisms often grew as a translucent film.

Growth of most strains appeared to be stimulated by addition of either $2 \%$ Oxgall (Difco) or rumen fluid (15\%) to the culture media. All biochemical characteristics of the strains were determined in the presence of added bile. In the absence of a fermentable carbohydrate, little or no growth occurred in peptone-yeast extract basal medium (2) even in

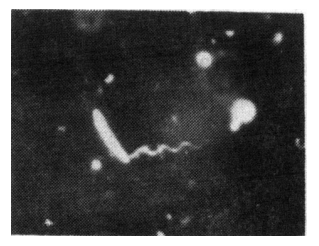

FIG. 1. Photograph through a dark-field microscope of a 24-h-old culture of $E$. plexicaudatum in $E$ medium. $\times 1500$.

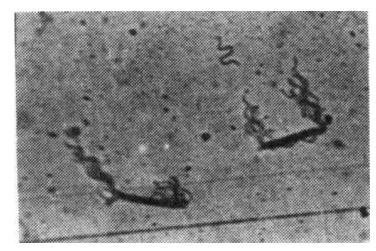

FIG. 2. Photograph of E. plexicaudatum stained by King's modification of the Leifson flagella stain. Cells from a 24-h-old culture in E medium. $\times 1500$. 
the presence of added bile or rumen fluid. The variations in carbohydrate fementation by the 15 strains are listed in Table 1. The following carbohydrates were not fermented by any strain: adonitol, dulcitol, erythritol, glycerol, gly cogen, inositol, mannitol, melezitose, and sorbose. Indole, catalase, and $\mathrm{H}_{2} \mathrm{~S}$ were not produced. None of the strains digested milk or meat; gelatin was partially liquefied after 1 week of incubation. Starch was not hydrolyzed; all of the strains hydrolyzed esculin. The optimal temperature for growth was $37 \mathrm{C}$; very little growth occurred at 25 or $30 \mathrm{C}$.

Acids produced from glucose were butyric $(0.8$ to $2.8 \mathrm{meq} / 100 \mathrm{ml})$ and acetic $(0.1$ to 0.15 meq $/ 100 \mathrm{ml}$ ); trace amounts of pyruvic and succinic acids also were produced. From peptone-yeast extract broth, acetic acid $(0.20$ to $0.40 \mathrm{meq} / 100 \mathrm{ml}$ ) and smaller amounts of butyric acid $(0.10$ to $0.15 \mathrm{meq} / 100 \mathrm{ml})$ were produced. The organism also produced $\mathrm{H}_{2}$; production of $\mathrm{CO}_{2}$ could not be tested due to the presence of bicarbonate in the medium.

The guanine plus cytosine content of the deoxyribonucleic acid of the type strain was 44 $\mathrm{mol} \%$.

Type strain: Virginia Polytechnic Institute (VPI) 7582 (= American Type Culture Collection [ATCC] 27514); this strain was isolated from a mouse.

This species can be recognized as a member

TABLE 1. Variations in acid production from carbohydrates by 15 strains of Eubacterium plexicaudatum

\begin{tabular}{|c|c|c|}
\hline Carbohydrate & $\begin{array}{l}\text { No. of } \\
\text { strains producing } \\
\text { acid }^{a}\end{array}$ & $\begin{array}{c}\text { Type strain } \\
(\text { ATCC 27514) }\end{array}$ \\
\hline Amygdalin $\ldots$ & 4 & - \\
\hline Arabinose ... & 15 & + \\
\hline Cellobiose ... & 15 & + \\
\hline Fructose .... & 15 & + \\
\hline Galactose ... & 15 & + \\
\hline Glucose ..... & 15 & + \\
\hline Inulin $\ldots \ldots$ & 2 & - \\
\hline Lactose .... & 15 & + \\
\hline Maltose .... & 15 & + \\
\hline Mannose .... & 15 & + \\
\hline Melibiose .... & 15 & + \\
\hline Raffinose $\ldots$ & 15 & + \\
\hline Ribose ..... & 11 & + \\
\hline Salicin ..... & 11 & + \\
\hline Sorbitol ..... & 4 & + \\
\hline Sucrose .... & 15 & + \\
\hline Trehalose ... & 13 & + \\
\hline Xylose ..... & 15 & + \\
\hline
\end{tabular}

${ }^{a} \mathrm{pH} 6.0$ to 7.0 .

$b_{+, \text {Acid produced; -, acid not produced. }}$ of the genus Eubacterium by the gram-positive reaction of young cultures and the production of butyric acid. Differentiation from other members of the genus is based on the morphology and biochemical characteristics described in this report.

\section{DISCUSSION}

Comparison of the cultural characteristics, morphology, and fermentation products of the strains of this group with presently adequately described species of anaerobic bacteria indicates that this organism represents a species which has not been previously named. However, other workers may have isolated this organism in the past. Gordon and Dubos (1) published photographs of an organism with similar morphology but reported no cultural characteristics. For the strains described in this report we propose the name Eubacterium plexicaudatum. The species name is derived from the Latin noun plexus, meaning a twisting or braiding, and from the modern Latin adjective caudatus, meaning equipped with a tail. This specific epithet refers to the tuft of subpolar flagella that are twisted together to form the "large flagellum" often visible by dark-field or phase-contrast microscopy of cecal preparations.

Many strains of this species are difficult to grow, and the variations obtained in carbohydrate fermentation may be due to this characteristic. The organisms are quite susceptible to oxidation and are difficult to preserve in a freeze-dried or frozen state. When freeze-dried cultures are reconstituted, care must be taken to reduce oxygen exposure to a minimum. In our hands the organism survived well when streaked on BHI roll-tubes, stored at $37 \mathrm{C}$, and transferred monthly.

This species represents a significant portion of the cecal flora of some mice and rats in that it is present in numbers as high as $2 \times 10^{10} / \mathrm{g}$ (wet weight). This would correspond to approximately 10 to $20 \%$ of the organisms present. The presence of the organism in wild mice and rats indicates that it is a "normal" inhabitant of the rodent cecum and that its presence in the laboratory mice was not due to either the type of diet or the "pathogen-free" nature of the mouse colony.

The production of relatively large amounts of butyric acid by the organism suggests that this organism may contribute to the inhibition of coliform bacteria in the ceca of mice. Lee and Gemmell (4) have shown that butyric acid in mouse ceca inhibits the proliferation of 
coliform bacteria. Certain of the fusiform. shaped bacteria in mouse ceca have been reported to be members of the genus Fusobacterium (1), and all members of this genus produce butyric acid. Thus, several species may be involved in the production of the large amounts of butyric acid found in mouse ceca. When the majority of species present in the ceca of rodents have been fully characterized, it may be possible to determine which characteristics are of major importance in repressing the growth of coliforms and pathogenic organisms in this environment.

\section{ACKNOWLEDGMENTS}

Preliminary phases of this work were initiated in the Departments of Pharmacology and Oral Biology at the Chandler Medical Center, Lexington, Ky. During this time, T. D. Wilkins, under the direction of Helmut Gordon, was supported by Public Health Service postdoctoral fellowship 5 FO2 AI 34, 476-02 from the National Institute of Allergy and Infectious Diseases. Partial support from Public Health Service grants FR-05314 and DE03053 from the Division of Research Facilities and Resources and the National Institute of Dental Research, respectively, to the medical center is acknowledged. Later phases were completed at the Virginia Polytechnic Institute and State University Anaerobe Laboratory and were supported by Public Health Service grant 14604 from the National Institute of General Medical Sciences.

The determination of mole percent guanine plus cytosine was performed for us by John Johnson; the analysis for hydrogen was performed by $R$. M. Smibert. T. O. MacAdoo (Department of Foreign Languages) was a valuable consultant on Latin.

\section{REPRINT REQUESTS}

Address reprint requests to: Tracy D. Wilkins, Anaerobe Laboratory, P. O. Box 49, Blacksburg, Virginia 24060.

\section{LITERATURE CITED}

1. Gordon, J. H., and R. Dubos. 1970. The anaerobic bacterial flora of the mouse cecum. J. Exp. Med. 132:251-260.

2. Holdeman, L. V., and W. E. C. Moore. (ed.) 1972. Anaerobe laboratory manual. Virginia Polytechnic Institute Anaerobe Laboratory, Blacksburg, Va. 24061.

3. Law, J. H., and R. A. Slepecky. 1961. Assay of poly- $\beta$-hydroxybutyric acid. J. Bacteriol. 82:33-36.

4. Lee, A., and E. Gemmell. 1972. Changes in the mouse intestinal microflora during weaning: role of volatile fatty acids. Infect. Immunity 5:1-7.

5. Marmur, J., and P. Doty. 1962. Determination of the base composition of deoxyribonucleic acid from its thermal denaturation temperature. J. Mol. Biol. 5:109-118. 